\title{
Association of abdominal subcutaneous fat thickness with hepatic steatosis, liver enzymes, and serum lipids in obese children
}

\author{
Levent Soydan M.D. ${ }^{a}$, Narin Akıcı M.D. ${ }^{b}$ and Yesim Coskun M.D. ${ }^{c}$
}

\begin{abstract}
Introduction. Childhood obesity can cause hyperlipidemia and hepatic steatosis at early age and chronic disease complications in adult life. We aimed to evaluate the relationship between abdominal subcutaneous fat thickness (ASFT) and hepatic steatosis, serum lipid and transaminase levels in obese children.

Population and methods. A retrospective study was conducted with children (aged 4-18 years) who presented to outpatient clinic due to obesity. Associations between ASFT as assessed by ultrasonography (US) and hepatic steatosis, alanine transaminase (ALT), aspartate transaminase(AST) and serum lipid profile were evaluated.
\end{abstract}

Results. We identified 95 children, all of which were diagnosed as having hepatic steatosis; the most common type was grade $1(73.6 \%$, $\mathrm{n}: 70)$, followed by grade $2(21.1 \%)$ and grade 3 $(5.3 \%)$. The mean values of midline and flank ASFT were measured as $38.48 \pm 11.53 \mathrm{~mm}$ and $20.91 \pm 8.00 \mathrm{~mm}$ in grade $1 ; 41.23 \pm 10.03$ and $19.84 \pm 6.75$ in grade 2 and $63.12 \pm 12.08$ and $23.22 \pm 5.92$ in grade 3 hepatic steatosis, respectively. Midline and flank ASFT correlated positively with triglycerides in grade 3 steatosis, while midline ASFT correlated with body mass index, total cholesterol, low-density lipoprotein cholesterol, and AST (r: 0.9; p: 0.037; r: 0.648, p: $0.001 ;$ r: 0.387, p: $0.001 ;$ r: 0.406, p: 0.001, r: 0.463 , p: 0.001; respectively) in grade 1 steatosis.

Conclusion. ASFT as assessed by US may be of predictive value for hyperlipidemia in grade 3 and for hypercholesterolemia in grade 1 hepatic steatosis in obese children.

Keywords: subcutaneous fat abdominal, pediatric obesity, liver steatoses, lipid metabolism.

http:/ / dx.doi.org/10.5546/ aap.2021.eng.114

To cite: Soydan L, Akıc1 N, Coskun Y. Association of abdominal subcutaneous fat thickness with hepatic steatosis, liver enzymes, and serum lipids in obese children. Arch Argent Pediatr 2021;119(2):114-122.

\section{GLOSSARY}

ALT: Alanine aminotransferase.

ASFT: Abdominal subcutaneous fat thickness.

AST: Aspartate aminotransferase.

BMI: Body mass index.

CT: Computed tomography.

HDL-C: High-density lipoprotein

cholesterol.

LDL-C: Low-density lipoprotein

cholesterol.

MRI: Magnetic resonance imaging.

NAFLD: Nonalcoholic fatty liver

disease.

TC: Total cholesterol.

TG: Triglyceride.

US: Ultrasonography.

\section{INTRODUCTION}

Pediatric obesity is a major health problem that is characterized by an excess of adiposity or body fat. It contributes to medical, physical, and emotional problems during childhood which may lead to high morbidity in adulthood. ${ }^{1}$ According to World Health Organization, the prevalence of obesity has increased over the past three decades with an annual increase of $0,5-1 \% .^{2,3}$ Obesity is a multifactorial condition affected by both genetic and non-genetic factors. ${ }^{1,2}$ It is defined by the body mass index (BMI) which has a strong correlation with adiposity. ${ }^{4}$

Childhood obesity often continues into adulthood obesity, which is strongly linked to insulin resistance, diabetes mellitus type 2 , hypertension, dyslipidemia, fatty liver, asthma, sleep apnea, and orthopedic problems. ${ }^{5-8}$ Obesity can be associated with biochemical abnormalities that start in childhood. Serum lipid profile, especially triglyceride and total cholesterol (TC) levels and serum 
alanine / aspartate aminotransferase (ALT/ AST) levels may be above the normal range in obese children..$^{910}$ Childhood obesity can also be associated with hepatic steatosis, which is defined as the accumulation of fat in the liver, especially in the form of triglycerides. Although hepatic steatosis is generally self-limiting, it may progress to nonalcoholic fatty liver disease (NAFLD) and liver cirrhosis. ${ }^{11,12}$

Body adipose tissue amount and distribution is closely associated with obesity, and attempts have been made to assess visceral and subcutaneous fat tissue, using ultrasonography (US), dual-energy X-ray absorptiometry, computed tomography (CT) and magnetic resonance imaging (MRI). ${ }^{13}$ To investigate the association between body adiposity and obesity-related risk factors, various studies focused more on anthropometric measures and visceral adiposity. The ability of abdominal subcutaneous fat thickness (ASFT) as the sole parameter to reflect the degree of hepatic steatosis and hyperlipidemia has not been clearly established yet. US can be used both to diagnose hepatic steatosis and to measure ASFT. ${ }^{14-16}$ If ASFT can predict these obesity-related parameters in obese children, then sonographic assessment of ASFT may be added to the initial workup of obese children to identify high risk obese children since US is a non-invasive, easy-to-use, widely available, and safe imaging modality. ${ }^{13}$
In this study, we aimed to evaluate the association between ASFT and hepatic steatosis, serum lipid and transaminase levels in obese children.

\section{POPULATION AND METHODS}

This retrospective study was conducted with children who were presented to pediatric outpatient clinic due to obesity between May 2016 and April 2018 in Haydarpasa Numune Training and Research Hospital. We defined a pediatric patient as obese if her/his BMI was $\geq 95$ th percentile. ${ }^{17}$ We excluded those obese children with chronic liver diseases, infectious liver diseases, hepatomegaly, congenital dyslipidemias or metabolic diseases.

Data on children's height and weight had been immediately assessed at admission. These data were then combined with the age and gender of the children to calculate the BMI using the mathematical formula of weight-for-height index. Serum lipid (TC, low-density lipoproteincholesterol [LDL-C], high-density lipoproteincholesterol [HDL-C], triglycerides [TG]) and transaminase levels were obtained in the fasting state by venipuncture within 7 days of outpatient admission.

Conventional US was performed by a single radiologist who had information about the clinical presentation of the patient but was unaware of

FIGURE 1. Measurement of flank abdominal subcutaneous fat thickness from skin surface (between calipers)

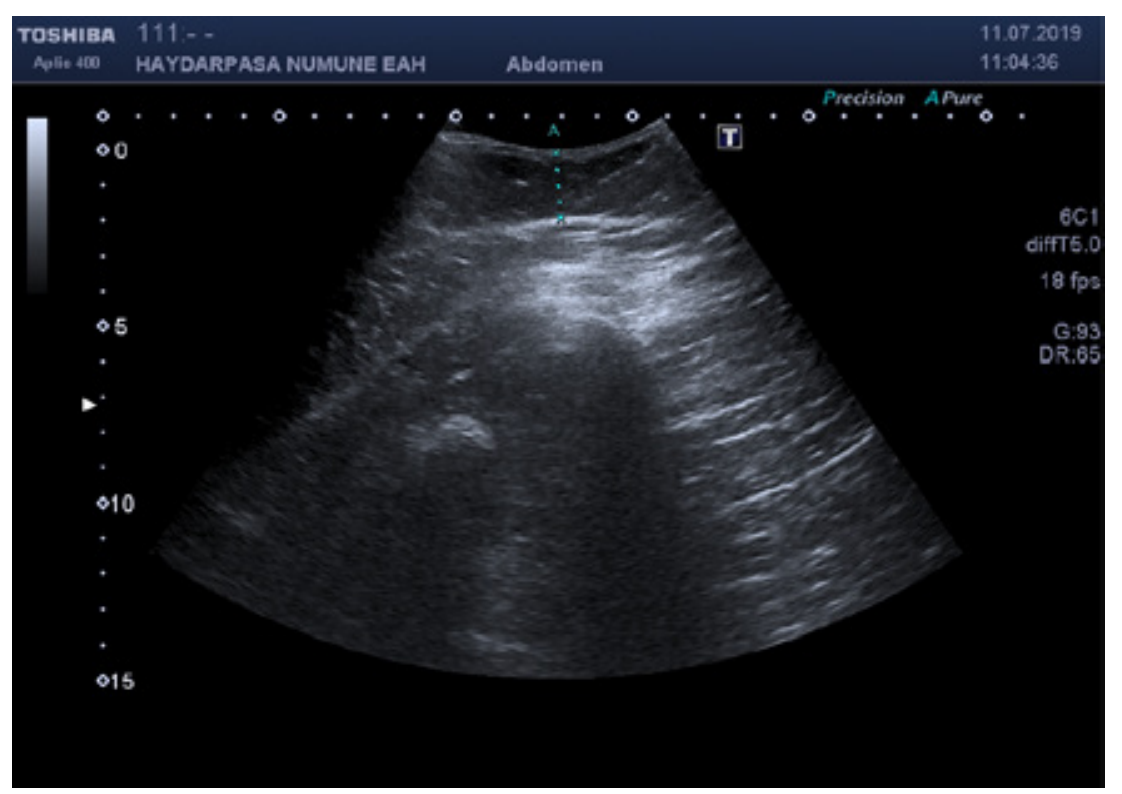


laboratory findings. The procedure was powered via an Aplio 500 ultrasound system (Toshiba/ Canon, Japan) with linear and convex transducers (frequency bandwidth 18 and 3.5-6 MHz respectively) in a standardized manner: ASFT was measured with minimal pressure applied by the US probe during normal respiration when the child was in the supine position. The midline ASFT was measured in the transverse plane, one centimeter below the umbilicus level, and the flank ASFT was measured within the same transverse plane on both the right and left flanks, approximately at the level of each anterior superior iliac spine. The mean value of both sides was taken as flank ASFT. The subcutaneous fat thickness was defined as the distance between the skin surface and the outer margin of the abdominal muscle layer (Figure $1 \mathcal{E} 2$ ).

The hepatic steatosis score was assessed by conventional US as follows: slight and diffuse increase in fine parenchymal echoes with normal visualization of diaphragm and portal vein borders was defined as grade 1 ; moderate and diffuse increase in fine echoes with slightly impaired visualization of portal vein borders and diaphragm was defined as grade 2 , and fine echoes with poor or no visualization of portal vein borders, diaphragm, and posterior portion of the right lobe was defined as grade 3 steatosis. ${ }^{18}$
Ethical considerations: The study protocol was approved by the Ethics Committee of Zeynep Kamil Maternity and Children's Diseases Training and Research Hospital (approval no: 2018-84). The study was performed according to the principles laid out in the Declaration of Helsinki.

Statistical analysis: Statistical analysis was performed using NCSS (Number Cruncher Statistical System) 2007 (Kaysville, Utah, USA) software. The descriptive data were expressed as the numbers and percentage or the mean, standard deviation, median, range, and z-scores; where appropriate. Kruskal Wallis test and Mann Whitney U test for Bonferroni correction were used in the comparison of three and more groups that showed non-normal distribution. The Fisher Freeman Halton test was used to compare the categorical variables. Correlation between parametric variables was tested through Spearman correlation analysis. An overall type-1 error level of $5 \%$ was used to infer statistical significance.

\section{RESULTS}

We identified 95 obese children (boys $57.9 \%$ ); the mean age was $11.8 \pm 3.9$ years (range: 4-18 years). The mean BMI was 28.0 with a mean $\mathrm{z}$-score of $-1.7 \mathrm{~kg} / \mathrm{m}^{2}$ (Table 1 ).

We detected hepatic steatosis in all children,

FIGURE 2. Measurement of midline abdominal subcutaneous fat thickness from skin surface (between calipers)

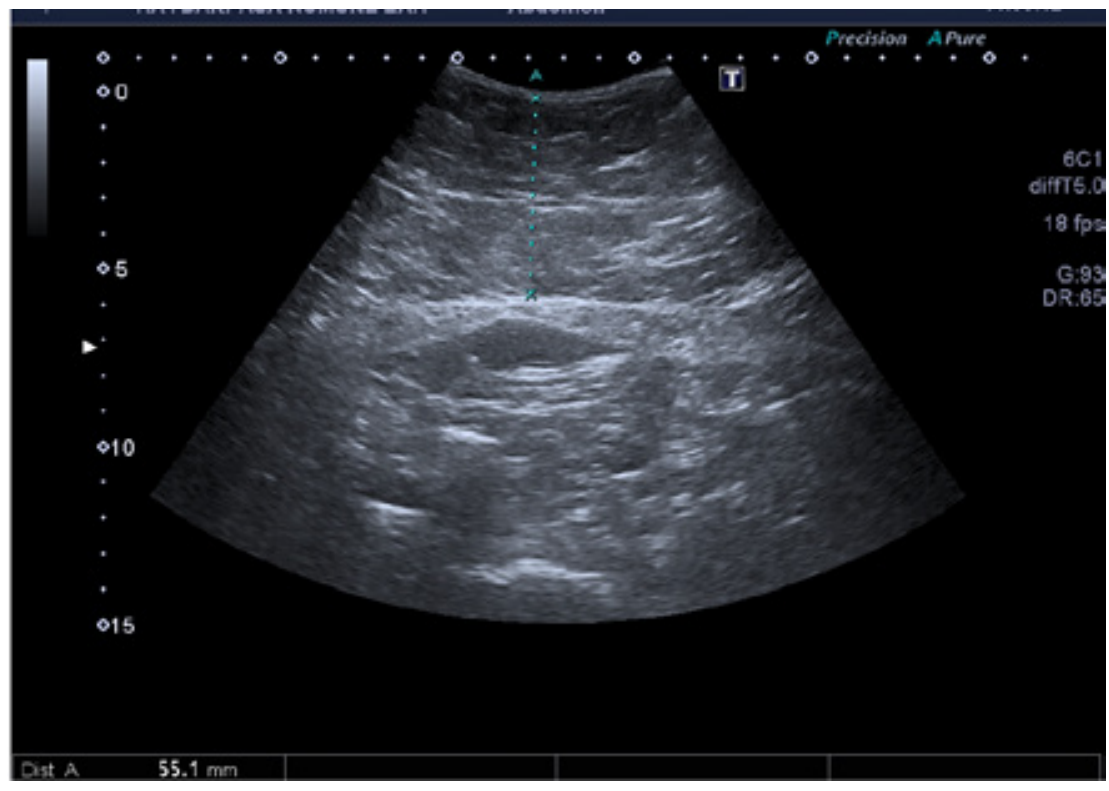


TABLE 1. The demographic and clinical characteristics of the patients

\begin{tabular}{|c|c|c|}
\hline Age (year) & $\begin{array}{l}\text { Min-Max (median) } \\
\text { mean } \pm \text { standart deviation }\end{array}$ & $\begin{array}{l}4-18(11) \\
11.8 \pm 3.9\end{array}$ \\
\hline Gender, n (\%) & $\begin{array}{l}\text { Female } \\
\text { Male }\end{array}$ & $\begin{array}{l}40(42.1) \\
55(57.9)\end{array}$ \\
\hline BMI $\left(\mathrm{kg} / \mathrm{m}^{2}\right)$ & $\begin{array}{l}\text { Mean } \\
\text { Mean z-score }\end{array}$ & $\begin{array}{l}28.02 \\
-1.7\end{array}$ \\
\hline TG (mg/dl) & $\begin{array}{l}\text { Min-Max (median) } \\
\text { mean } \pm \text { standart deviation }\end{array}$ & $\begin{array}{l}35-292(93) \\
102.03 \pm 44.43\end{array}$ \\
\hline $\mathrm{TC}(\mathrm{mg} / \mathrm{dl})$ & $\begin{array}{l}\text { Min-Max (median) } \\
\text { mean } \pm \text { standart deviation }\end{array}$ & $\begin{array}{l}74-279(166) \\
166.41 \pm 37.59\end{array}$ \\
\hline HDL-C (mg/dl) & $\begin{array}{l}\text { Min-Max (median) } \\
\text { mean } \pm \text { standart deviation }\end{array}$ & $\begin{array}{l}23-144(45) \\
47.78 \pm 18.38\end{array}$ \\
\hline LDL-C (mg/dl) & $\begin{array}{l}\text { Min-Max (median) } \\
\text { mean } \pm \text { standart deviation }\end{array}$ & $\begin{array}{l}32-154(105) \\
101.31 \pm 27.85\end{array}$ \\
\hline AST (IU/L) & $\begin{array}{l}\text { Min-Max (median) } \\
\text { mean } \pm \text { standart deviation }\end{array}$ & $\begin{array}{l}11-94(22) \\
24.72 \pm 11.84\end{array}$ \\
\hline ALT (IU/L) & $\begin{array}{l}\text { Min-Max (median) } \\
\text { mean } \pm \text { standart deviation }\end{array}$ & $\begin{array}{l}9-109(21) \\
26.22 \pm 17.13\end{array}$ \\
\hline Midline ASFT (cm) & $\begin{array}{l}\text { Min-Max (median) } \\
\text { mean } \pm \text { standart deviation }\end{array}$ & $\begin{array}{l}16-80(40.60) \\
40.36 \pm 12.43\end{array}$ \\
\hline Flank ASFT (cm) & $\begin{array}{l}\text { Min-Max (median) } \\
\text { mean } \pm \text { standart deviation }\end{array}$ & $\begin{array}{l}7-44.4(20.50) \\
20.80 \pm 7.63\end{array}$ \\
\hline Hepatic steatosis, n (\%) & $\begin{array}{l}\text { Grade } 1 \\
\text { Grade } 2 \\
\text { Grade } 3\end{array}$ & $\begin{array}{l}70(73.7) \\
20(21.1) \\
5(5.3)\end{array}$ \\
\hline
\end{tabular}

BMI: body mass index, TG: triglyceride, TC: total cholesterol, HDL-C: high density lipoprotein-cholesterol, LDL-C: low density lipoprotein-cholesterol, AST: aspartate aminotransferase, ALT: alanine aminotransferase, ASFT: abdominal subcutaneous fat thickness.

TABLE 2. Demographic and clinical characteristics of groups according to the grade of hepatic steatosis

\begin{tabular}{|c|c|c|c|c|c|}
\hline & & Grade $1(n=70)$ & $\begin{array}{l}\text { Hepatic steatosis } \\
\text { Grade } 2(n=20)\end{array}$ & Grade $3(n=5)$ & $\begin{array}{c}\text { Test value } \\
p\end{array}$ \\
\hline Age (year) & $\begin{array}{l}\text { Min-Max (median) } \\
\text { mean } \pm \text { standart deviation }\end{array}$ & $\begin{array}{c}4-18(10) \\
11.19 \pm 3.99\end{array}$ & $\begin{array}{c}8-18(12) \\
13.05 \pm 3.2\end{array}$ & $\begin{array}{l}13-16(14) \\
14.6 \pm 1.34\end{array}$ & $\begin{array}{l}\chi^{2}: 6.833 \\
{ }^{\mathrm{a}} 0.033^{*}\end{array}$ \\
\hline Gender, n (\%) & $\begin{array}{l}\text { Female } \\
\text { Male }\end{array}$ & $\begin{array}{l}35(87.5) \\
35(63.6)\end{array}$ & $\begin{array}{c}3(7.5) \\
17(30.9)\end{array}$ & $\begin{array}{l}2(5.0) \\
3(5.5)\end{array}$ & $\begin{array}{l}\chi^{2}: 8.165 \\
{ }^{b} 0.013^{*}\end{array}$ \\
\hline BMI $\left(\mathrm{kg} / \mathrm{m}^{2}\right)$ & $\begin{array}{l}\text { Mean } \\
\text { mean z-score }\end{array}$ & $\begin{array}{l}26.7 \\
-0.2\end{array}$ & $\begin{array}{c}30.9 \\
0.5\end{array}$ & $\begin{array}{c}34.8 \\
1.2\end{array}$ & $\begin{array}{l}\chi^{2}: 14.487 \\
{ }^{a} 0.001^{* *}\end{array}$ \\
\hline TG (mg/dl) & $\begin{array}{l}\text { Min-Max (median) } \\
\text { mean } \pm \text { standart deviation }\end{array}$ & $\begin{array}{l}35-292(89.5) \\
97.44 \pm 43.65\end{array}$ & $\begin{array}{c}43-208(110) \\
115.45 \pm 49.08\end{array}$ & $\begin{array}{l}83-142(102) \\
112.6 \pm 26.03\end{array}$ & $\begin{array}{l}\chi^{2}: 3.529 \\
{ }^{a} 0.171\end{array}$ \\
\hline $\mathrm{TC}(\mathrm{mg} / \mathrm{dl})$ & $\begin{array}{l}\text { Min-Max (median) } \\
\text { mean } \pm \text { standart deviation }\end{array}$ & $\begin{array}{c}74-279(168) \\
167.46 \pm 38.84\end{array}$ & $\begin{array}{l}100-219(166) \\
164.75 \pm 36.35\end{array}$ & $\begin{array}{l}122-201(157) \\
158.4 \pm 28.11\end{array}$ & $\begin{array}{l}\chi^{2}: 0.753 \\
{ }^{a} 0.686\end{array}$ \\
\hline HDL-C (mg/dl) & $\begin{array}{l}\text { Min-Max (median) } \\
\text { mean } \pm \text { standart deviation }\end{array}$ & $\begin{array}{c}23-144(47) \\
50.79 \pm 20.12\end{array}$ & $\begin{array}{l}25-56(39.5) \\
39.25 \pm 8.17\end{array}$ & $\begin{array}{l}30-48(40) \\
39.8 \pm 6.5\end{array}$ & $\begin{array}{l}\chi^{2}: 11.745 \\
{ }^{a} 0.003^{* *}\end{array}$ \\
\hline LDL-C (mg/dl) & $\begin{array}{l}\text { Min-Max (median) } \\
\text { mean } \pm \text { standart deviation }\end{array}$ & $\begin{array}{l}32-154(106.5) \\
101.39 \pm 29.38\end{array}$ & $\begin{array}{c}60-145(103.5) \\
102.2 \pm 24.12\end{array}$ & $\begin{array}{l}66-131(98) \\
96.6 \pm 23.37\end{array}$ & $\begin{array}{l}\chi^{2}: 0.312 \\
{ }^{a} 0.856\end{array}$ \\
\hline AST (IU/L) & $\begin{array}{l}\text { Min-Max (median) } \\
\text { mean } \pm \text { standart deviation }\end{array}$ & $\begin{array}{c}11-49(20) \\
21.76 \pm 6.95\end{array}$ & $\begin{array}{c}20-75(27) \\
31.75 \pm 13.18\end{array}$ & $\begin{array}{l}17-94(29) \\
38 \pm 31.89\end{array}$ & $\begin{array}{l}\chi^{2}: 18.875 \\
{ }^{\mathrm{a}} 0.001^{* *}\end{array}$ \\
\hline ALT (IU/L) & $\begin{array}{l}\text { Min-Max (median) } \\
\text { mean } \pm \text { standart deviation }\end{array}$ & $\begin{array}{c}9-55(18) \\
19.86 \pm 8.94\end{array}$ & $\begin{array}{l}19-109(37) \\
45.1 \pm 22.43\end{array}$ & $\begin{array}{c}18-70(37) \\
39.8 \pm 20.07\end{array}$ & $\begin{array}{l}\chi^{2}: 35.707 \\
{ }^{\mathrm{a}} 0.001^{* *}\end{array}$ \\
\hline
\end{tabular}

${ }^{a}$ Kruskal Wallis Test. ${ }^{b}$ FisherFreeman. ${ }^{*} \mathrm{p}<0.05 .{ }^{* *} \mathrm{p}<0.01$.

BMI: body mass index, TG: triglyceride, TC: total cholesterol, HDL-C: high density lipoprotein-cholesterol,

LDL-C: low density lipoprotein-cholesterol, AST: aspartate aminotransferase, ALT: alanine aminotransferase. 
where the most common type was grade $1(73.6 \%$, n: 70$)$, followed by grade $2(21.1 \%, \mathrm{n}: 20)$ and grade $3(5.3 \%, \mathrm{n}: 5)$. The mean age of the patients with grade 2 steatosis was significantly higher than those with grade 1 (p: 0.041). Grade 1 and 2 steatosis were more common among males compared to females (p: 0.027 and p: 0.018, respectively). Patients with grade 2 steatosis had significantly higher BMI than that in those with grade 1 steatosis (p: 0.001). The mean AST and ALT levels were lower in patients with grade 1 steatosis compared to those in grade 2 steatosis (p: 0.0035 and $\mathrm{p}<0.0001$ ). While TC and TG levels did not differ in terms of steatosis grades, patients with grade 1 steatosis had higher mean HDL levels than that in those with grade 2 (p: 0.0003) and grade 3 (p: 0.0141).
We found higher midline ASFT in patients with grade 3 steatosis than that in those with grade 1 (p: 0.0086 ) or grade 2 steatosis (p: 0.0114). The flank ASFT was similar across the different grades of hepatic steatosis (Table 3 ).

There was also a positive correlation between BMI and midline ASFT in patients with grade 1 ( $\mathrm{r}: 0.648, \mathrm{p}: 0.001$ ) and grade 2 steatosis (r: 0.558, p: 0.011). Among transaminases, AST correlated both with midline and flank ASFT in grade 1 (r: 0.463, p: 0.001 and r: 0.431, p: 0.001; respectively) and with flank ASFT in grade 3 hepatic steatosis (r: 0.900, p: 0.037). There was also a positive correlation between midline ASFT and LDL-C and TC levels in patients with grade 1 steatosis (r: 0.406, p: 0.001 and r: $=0.387$, p: 0.001; respectively). In patients with grade 3 steatosis,

TABLE 3. Evaluation of midline and flank ASFT according to grade of hepatic steatosis

\begin{tabular}{|c|c|c|c|c|c|}
\hline & & Grade $1(n=70)$ & $\begin{array}{c}\text { Steatosis } \\
\text { Grade } 2(n=20)\end{array}$ & Grade $3(n=5)$ & $\begin{array}{c}\text { Test value } \\
p\end{array}$ \\
\hline Midline ASFT (mm) & $\begin{array}{l}\text { Min-Max (median) } \\
\text { mean } \pm \text { standart deviation }\end{array}$ & $\begin{array}{c}16-61(38.5) \\
38.48 \pm 11.53\end{array}$ & $\begin{array}{c}25-57(42.5) \\
41.23 \pm 10.03\end{array}$ & $\begin{array}{l}46.6-80(64) \\
63.12 \pm 12.08\end{array}$ & $\begin{array}{l}\chi^{2}: 11.762 \\
{ }^{\mathrm{a}} 0.003^{* *}\end{array}$ \\
\hline Flank ASFT (mm) & $\begin{array}{l}\text { Min-Max (median) } \\
\text { mean } \pm \text { standart deviation }\end{array}$ & $\begin{array}{l}7-44.4(20.5) \\
20.91 \pm 8.00\end{array}$ & $\begin{array}{c}11-37.4(18.95) \\
19.84 \pm 6.75\end{array}$ & $\begin{array}{c}17-33(22) \\
23.22 \pm 5.92\end{array}$ & $\begin{array}{l}\chi^{2}: 1.449 \\
\mathrm{a} 0.485\end{array}$ \\
\hline
\end{tabular}

${ }^{\text {a }}$ Kruskal Wallis Test. ${ }^{* *} \mathrm{p}<0.01$.

ASFT: abdominal subcutaneous fat thickness.

TABLE 4. Associations of midline and flank ASFT with BMI, TG, TC, HDL-C, LDL-C, AST, and ALT according to grade of hepatic steatosis

\begin{tabular}{lccccccc}
\hline & & \multicolumn{3}{c}{$\begin{array}{c}\text { Midline ASFT } \\
\text { Hepatic steatosis } \\
\text { Grade 2 }\end{array}$} & Grade 3 & Grade 1 & $\begin{array}{c}\text { Flank ASFT } \\
\text { Hepatic steatosis } \\
\text { Grade 2 }\end{array}$ \\
\hline BMI & $\mathbf{r}$ & 0.648 & 0.558 & 0.000 & 0.233 & 0.149 & 0.300 \\
& $\mathbf{p}$ & $0.001^{* *}$ & $0.011^{*}$ & 1.000 & 0.052 & 0.531 & 0.624 \\
TG & $\mathbf{r}$ & 0.009 & 0.148 & 0.900 & 0.154 & 0.048 & 0.900 \\
& $\mathbf{p}$ & 0.938 & 0.534 & $0.037^{*}$ & 0.202 & 0.840 & $0.037^{*}$ \\
TC & $\mathbf{r}$ & 0.387 & 0.041 & 0.700 & 0.089 & 0.080 & 0.800 \\
& $\mathbf{p}$ & $0.001^{* *}$ & 0.862 & 0.188 & 0.464 & 0.738 & 0.104 \\
HDL-C & $\mathbf{r}$ & 0.216 & 0.412 & 0.200 & 0.198 & 0.067 & 0.300 \\
& $\mathbf{p}$ & 0.072 & 0.071 & 0.747 & 0.101 & 0.780 & 0.624 \\
LDL-C & $\mathbf{r}$ & 0.406 & 0.375 & 1.000 & 0.099 & 0.025 & 0.700 \\
& $\mathbf{p}$ & $0.001^{* *}$ & 0.104 & $0.001^{* *}$ & 0.415 & 0.917 & 0.188 \\
AST & $\mathbf{r}$ & 0.463 & 0.133 & 0.500 & 0.431 & 0.126 & 0.900 \\
& $\mathbf{p}$ & $0.001^{* *}$ & 0.575 & 0.391 & $0.001^{* *}$ & 0.598 & $0.037^{*}$ \\
ALT & $\mathbf{r}$ & 0.080 & 0.232 & 0.700 & 0.039 & 0.047 & 0.800 \\
& $\mathbf{p}$ & 0.513 & 0.325 & 0.188 & 0.750 & 0.845 & 0.104 \\
\hline
\end{tabular}

r: Spearman's correlation coefficient. ${ }^{*} \mathrm{p}<0.05 .{ }^{* *} \mathrm{p}<0.01$.

ASFT: abdominal subcutaneous fat thickness, BMI: body mass index, TG: triglyceride, TC: total cholesterol,

HDL-C: high density lipoprotein-cholesterol, LDL-C: low density lipoprotein-cholesterol, AST: aspartate aminotransferase,

ALT: alanine aminotransferase. 
a positive correlation existed between midline ASFT and TG (r: 0.900, p: 0.037) and LDL-C (r: 1.000, p: 0.001) levels). The flank ASFT was also positively correlated with TG level in grade 3 steatosis patients (r: 0.900, p: 0.037; Table 4).

\section{DISCUSSION}

Childhood obesity is a potential risk factor of several cardiovascular diseases including hypertension, dyslipidemia, diabetes, or sleep apnea in adulthood. Therefore, it is important to identify any obesity-related condition in childhood that may progress or lead to cardiometabolic complications in later life. ${ }^{1,2,19,20}$ This study provides important information regarding associations between ASFT and several biomarkers of such obesity-related conditions, which may be used to predict the risk of complications in obese children. Accordingly, our findings showed ASFT to potentially have a predictive value for dyslipidemia in obese pediatric patients, especially pronounced in those with grade I hepatic steatosis.

In childhood, hepatic steatosis is among the most common chronic hepatic diseases, and like in adults, it is a hallmark of NAFLD. ${ }^{21,22}$ Childhood obesity is associated with an increased risk of NAFLD, reaching a prevalence of up to $38 \%$ in adolesents. ${ }^{21}$ NAFLD includes hepatic steatosis, ranging from mild steatosis to steatohepatitis, and in rare cases, to cirrhosis with a tendency to progress. ${ }^{23,24}$ In our study, we found that the mean age for grade 3 hepatic steatosis was 14 years, whereas the mean age for grade 1 steatosis was 10 years. These findings suggest that early diagnosis and treatment of hepatic steatosis may be essential due to its tendency to progress. It has been reported that hepatic steatosis is more common in males with a male to female ratio of 2:1. ${ }^{24}$ We also found in our study that the number of male patients with grade 1 and 2 steatosis were higher than female patients, and the male gender carried higher risk for hepatic steatosis than the female patients. While obesity is known to attenuate gender differences in visceral steatosis, it was reported that pubertal and postpubertal boys were more likely to have increased abdominal fat tissue. ${ }^{25}$ Considering the mean age of our population, our findings seem to be consistent with the literature, though need to be clarified further with well-designed studies. It is also known that $20 \%$ to $80 \%$ of obese children with hepatic steatosis may have hypertriglyceridemia, high LDL-C and elevated transaminase levels. ${ }^{23,24}$

Apart from commonly used anthropometric measurements like skinfold thickness by caliper, US, CT, and MRI are imaging techniques that can be used to diagnose hepatic steatosis. ${ }^{13,18,26-28}$ Among these, US is a widely available, inexpensive, and radiation-free modality. ${ }^{26}$ It has been demostrated that liver US may also be used for quantifying steatosis in pediatric patients, and sonographic assessment of steatosis strongly correlates with the grade of steatosis on liver biopsy. ${ }^{28,29}$ The disadvantage of US is that if the liver contains less than $30 \%$ fat, the sensitivity decreases..$^{5,13}$ Although there are some reports for hepatic imaging modalities such as CT or MRI to diagnose steatosis, they are generally considered not feasible to be used for children because of their inherent cost, the potential need for sedation, relatively limited availability, and the inherent radiation with $\mathrm{CT} .{ }^{5,30}$ In our study, we used US to assess the liver parenchyma for steatosis, and found that all our patients had some degree of hepatic steatosis, albeit near three quarters with grade 1 .

Increased body adipocity seen in obesity has been linked to metabolic derangements, and there have been attempts to estimate the amount of body fat, using various anthropometric parameters. Other studies focused on any association between the amount of visceral and subcutaneous fat tissue with hepatic steatosis and dyslipidemia. ${ }^{31-35}$ Increased visceral fat has been consistently reported to be associated with both metabolic dysregulation and elevated liver enzymes. ${ }^{32,33}$ Yamaguci et al., found strong correlation between visceral adipose tissue and serum lipid profile and transaminases in obese children. ${ }^{33}$ Bibiloni et al. showed that body mass index and abdominal obesity were associated with the prevalence of at least one abnormal lipid level, and low HDL-C level was the most common dyslipidaemia among their patients. ${ }^{34}$ According to Bijari et al., there was a relationship between central obesity and adverse changes in lipid profiles, and they recommended screening children for central obesity for prevention of cardiovascular disease. ${ }^{35}$ Asayama et al. investigated the relationship between visceral fat thickness or the ratio of visceral to subcutaneous fat and various anthropometric parameters and reported that visceral adipose tissue correlated best with serum lipid values constituting a metabolic risk in children. ${ }^{32}$ All of these studies focused on the assessment of central and visceral 
obesity, which necessitates the use of crosssectional imaging such as CT or MRI.

However, there are few studies that investigated the link between subcutaneous fat amount and metabolic risk factors. ${ }^{36,37}$ Mager et al., showed in their study that the trunk subcutaneous fat taken as the sum of subcutaneous fat from abdominal, suprailiac and subscapular regions predicts abnormal liver biochemistry and dyslipdemia. ${ }^{37}$ Lee et al., used ASFT as the sole parameter to reflect the subcutaneous fat amount, and showed positive correlation of ASFT with BMI and hepatic steatosis. ${ }^{31}$ Our results also showed that midline ASFT elevated by $64.8 \%$ in grade 1 steatosis and $55.8 \%$ in grade 2 steatosis per $1 \mathrm{~kg} / \mathrm{m}^{2}$ increment in BMI, suggesting that an increase in BMI leads to fat deposition not only in the liver but also in the subcutaneous tissues. We also found a positive correlation between ASFT and BMI. Lee et al., found a correlation between ASFT and TC, LDL and ALT levels. ${ }^{31}$ Similarly, our results showed that elevation in TG and LDL levels in patients with grade 3 steatosis were associated with increased midline ASFT measurement. In addition, in our study, rising TG and AST levels were associated with increased flank ASFT measurements in grade 3 steatosis. We also demonstrated that ALT values of patients with grade 1 steatosis were significantly lower than those with grade 2 and grade 3 steatosis. These results suggest that increases in ASFT were associated with higher lipid metabolic derangement, higher grades of steatosis, and higher levels of AST. As such, sonographic measurement of ASFT may be added to the routine workup of obese children. In this way, children with a higher risk of dyslipidemia and hepatic compromise may be identified and treated earlier, thereby preventing obesity-related complications that may arise in later years. Once life-style modifications and appropriate diet are implemented, ASFT may also be used as an easyapplicable method to monitor children during this period as obesity-related risk parameters revert to normal ranges.

This study has some limitations. First, assessment of liver steatosis by US is operatordependent, subjective, and thus qualitative. In addition, if steatosis involves less than around $30 \%$ of liver parenchyma, the sensitivity and specificity become diminished. ${ }^{13,30}$ Hence, it may be less reproducible, and does not provide quantitative data about steatosis, although a large-scale study by Schlecht et al., reported high reproducibility and validity of US in measuring subcutaneous skin thickness, especially in non-obese children. ${ }^{15}$ Therefore, quantitative assessment of hepatic steatosis by MRI techniques in future studies may shed more light on this issue, and help confirm our results in a more reliable way. Secondly, our study lacked pathological verification of hepatic steatosis by liver biopsy as this would increase the reliability of our results by also clarifying other potential reasons included in the differential diagnosis. ${ }^{13}$ Next, we did not collect data about ethnicity or waist circumference of the patients, which should be considered in assessing the results. Another limitation was that the number of patients with grade 3 steatosis was small compared to patients in other groups, which highly decreases the certainties of interpretation of findings related to this subgroup. Therefore, we believe that further studies with larger number of grade 3 hepatic steatosis patients are needed to achieve more reliable conclusions.

\section{CONCLUSIONS}

In conclusion, both the midline and flank ASFT were positively correlated with triglycerides in obese children with grade 3 hepatic steatosis, whereas in grade I steatosis, the midline ASFT was positively correlated with BMI, TC, LDL-C, and AST. Nevertheless, these associations need to be confirmed in future large-scaled studies, possibly with modalities such as MRI, which can assess hepatic steatosis quantitatively.

\section{REFERENCES}

1. Güngör NK. Overweight and obesity in children and adolescents. J Clin Res Pediatr Endocrinol. 2014; 6(3):129-43.

2. Han JC, Lawlor D, Kimm SYS. Childhood Obesity-2010: Progress and Challenges. Lancet. 2010; 375(9727):1737-48.

3. Lobstein T, Baur L, Uauy R, IASO International Obesity TaskForce. Obesity in children and young people: a crisis in public health. Obes Rev. 2004; 5(Suppl 1):4- 104.

4. Nicolai JP, Lupiani JH, Wolf A J. An Integrative approach to obesity. In: Rakel D (ed). Integrative Medicine. $3^{\text {rd }}$ ed. Philadelphia, PA: Saunders-Elsevier; 2012.P.364-75.

5. Feldstein AE, Patton-Ku D, Boutelle KN. Obesity, Nutrition and Liver Disease in Children. Clin Liver Dis. 2014; 18(1):219-31.

6. Freedman DS, Khan LK, Serdula MK, Dietz WH, et al. The relation of childhod BMI to adult adiposity: the Bogalusa Heart Study. Pediatrics. 2005; 115(1):22-7.

7. Pulgaron ER, Delamater AM. Obesity and type 2 diabetes in children: epidemiology and treatment. Curr Diab Rep. 2014; 14(8):508.

8. Juonala M, Magnussen CG, Berenson GS, Venn A, et al. Childhood adiposity, adult adiposity, and cardiovascular risk factors. N Engl J Med. 2011; 365(20):1876-85.

9. Nobili V, Reale A, Alisi A, Morino G, et al. Elevated serum ALT in children presenting to the emergency unit: Relation- 
ship with NAFLD. Dig Liver Dis. 2009; 41(10):749-52.

10. Parekh S, Anania FA. Abnormal lipid and glucose metabolism in obesity: implications for nonalcoholic fatty liver disease. Gastroenterology. 2007; 132(6):2191-207.

11. Donnelly KL, Smith CI, Schwarzenberg SJ, Jessurun J, et al. Sources of fatty acids stored in liver and secreted via lipoproteins in patients withnonalcoholic fatty liver disease. J Clin Invest. 2005; 115(5):1343-51.

12. Ko JS, Yoon JM, Yang HR, Myung JK, et al. Clinical and histological features of nonalcoholic fatty liver disease in children. Dig Dis Sci. 2009; 54(10):2225-30.

13. Vajro P, Lenta S, Socha P, Dhawan A, et al. Diagnosis of nonalcholic fatty liver disease in children and adolescents: position paper of the ESPGHAN Hepatology Committee. J Pediatr Gastroenterol Nutr. 2012; 54(5):700-13.

14. SemizS,OzgörenE,SabirN.Comparisonofultrasonographic and anthropometric methods to assess body fat in childhood obesity. Int J Obes (Lond). 2007; 31(1):53-8.

15. Schlecht I, Wiggermann P, Behrens G, Fischer B, et al. Reproducibility and validity of ultrasound for the measurement of visceral and subcutaneous adipose tissues. Metabolism. 2014; 63(12):1512-9.

16. Wagner DR. Ultrasound as a tool to assess body fat. J Obes. 2013; 2013:280713.

17. Whitlock EP, Williams SB, Gold R, Smith PR, Shipman SA. Screening and interventions for childhood overweight: a summary of evidence for the US Preventive Services Task Force. Pediatrics. 2010; 116(1):e125-44.

18. Dasarathy S, Dasarathy J, Khiyami A, Joseph R, et al. Validity of real time ultrasound in the diagnosis of hepatic steatosis: a prospective study. J Hepatol. 2009; 51(6):1061-7.

19. Pulgarón ER. Childhood obesity: A review of increased risk for physical and psychological comorbidities. Clin Ther. 2013; 35(1):A18-32.

20. Burt Solorzano CM, McCartney CR. Obesity and the pubertal transition in girls and boys. Reproduction. 2010; 140(3):399-410.

21. Schwimmer JB, Deutsch R, Kahen T, Lavine JE, et al. Prevalence of fatty liver in children and adolescents. Pediatrics. 2006; 118(4):1388-93.

22. Jung JH, Jung MK, Kim KE, Kwon AR, et al. Ultrasound measurement of pediatric visceral fat thickness: correlations with metabolic and liver profiles. Ann Pediatr Endocrinol Metab. 2016; 21(2):75-80.

23. Sundaram SS, Zeitler P, Nadeau K. The metabolic syndrome and nonalcoholic fatty liver disease in children. Curr Opin Pediatr. 2009; 21(4):529-35.

24. Marzuillo P, Miraglia del Giudice E, Santoro N. Pediatric fatty liver disease: Role of ethnicity and genetics. World J Gastrenterol. 2014; 20(23):7347-55.

25. Staiano A, Katzmarzyk P. Ethnic and sex differences in body fat, visceral, and subcutaneous adiposity in children and adolescents. Int J Obes (Lond). 2012; 36(10):1261-9.

26. Sabir N, Sermez Y, Kazil S, Zencir M. Correlation of abdominal fat accumulation and liver steatosis: importance of ultrasonographic and anthropometric measurements. Eur J Ultrasound. 2001; 14(2-3):121-8.

27. Mazhar SM, Shiehmorteza M, Sirlin CB. Noninvasive assessment of hepatic steatosis. Clin Gastrenterol Hepatol. 2009; 7(2):135-40.

28. Shannon A, Alkhouri N, Carter-Kent C, Monti L, et al. Ultrasonographic quantitative estimaton of hepatic steatosis in children with NAFLD. J Pediatr Gastroenterol Nutr. 2011; 53(2):190-5.

29. Eifler RV. The role of ultrasonography in the measurement of subcutaneous and visceral fat and its correlation with hepatic steatosis. Radiol Bras. 2013; 46(5):273-8.

30. Vos M, Abrams S, Barlow S, Caprio S, et al. NASPGHAN clinical practice guideline for the diagnosis and treatment of Nonalcoholic Fatty Liver Disease in children: recommendations from the expert Committee on NAFLD (ECON) and the North American Society of Pediatric Gastroenterology, Hepatology and Nutrition (NASPGHAN). J Pediatr Gastroenterol Nutr. 2017; 64(2):31934.

31. Lee SH, Kim D, Baek MY, Tchah H, et al. Abdominal Subcutaneous Fat Thickness Measured by Ultrasonograph Correlates with Hyperlipidemia and Steatohepatitis in Obese Children. Pediatr Gastroenterol Hepatol Nutr. 2015; 18(2):108-14.

32. Asayama K, Dobashi K, Hayashibe H, Kodera K, et al. Threshold values of visceral fat measures and their anthropometric alternatives for metabolic derangement in Japanese obese boys. Int J Obes Relat Metab Disord. 2002; 26(2):208-13.

33. Yamaguchi J, Oguni T, Konishi K, Mino M. Abdominal adiposity with respect to the proportion of intra-abdominal visceral fat to extra-abdominal fat (VS ratio) in Japanese childhood obesity. Pathophysiol. 1996; 3(1):29-35.

34. Bibiloni MD, Salas R, De la Garza YE, Villarreal JZ, et al. Serum lipid profile, prevalence of dyslipidaemia, and associated risk factors among northern mexican adolescents. J Pediatr Gastroenterol Nutr. 2016; 63(5):544-9.

35. Bijari B, Taheri F, Chahkandi T, Kazemi T,et al. The relationship between serum lipids and obesity among elementary school in Birjand: a case control study. J Res Health Sci. 2015; 15(2):83-7.

36. Deeb A, Attia S, Mahmoud S, Elhaj G, Elfatih A. Dyslipidemia and fatty liver disease in overweight and obese children. J Obes. 2018; 2018:8626818.

37. Mager DR, Yap J, Rodriguez-Dimitrescu C, Mazurak V, et al. Anthropometric Measures of visceral and subcutaneous fat are important in the determination of metabolic dysregulation in boys and girls at risk for nonalcoholic fatty liver disease. Nutr Clin Pract. 2013; 28(1):101-11. 